
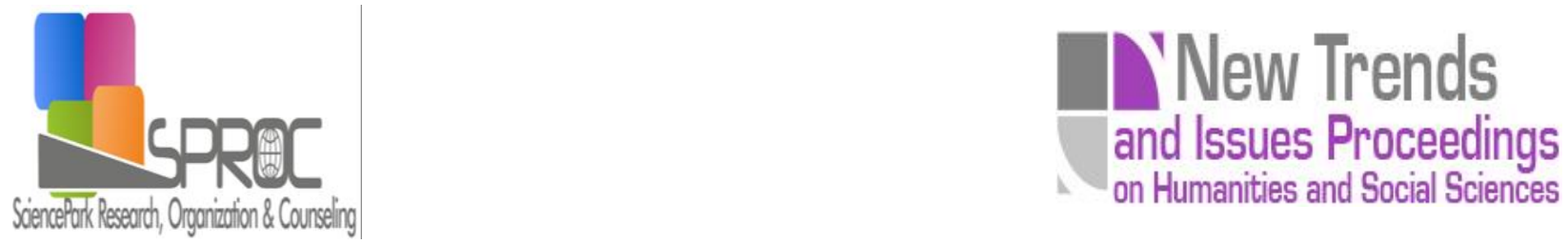

\title{
Behavioral indicators of innovators. A search protocol for a systematic literature review
}

Begona Montero-Fleta ${ }^{*}$

María Jose Perez-Penalver ${ }^{b}$

Lourdes Aznar-Masc

Suggested Citation:

Abstract 
1. Introduction

2. Contextual framework of the study 
$w$

$n$

c w

w 


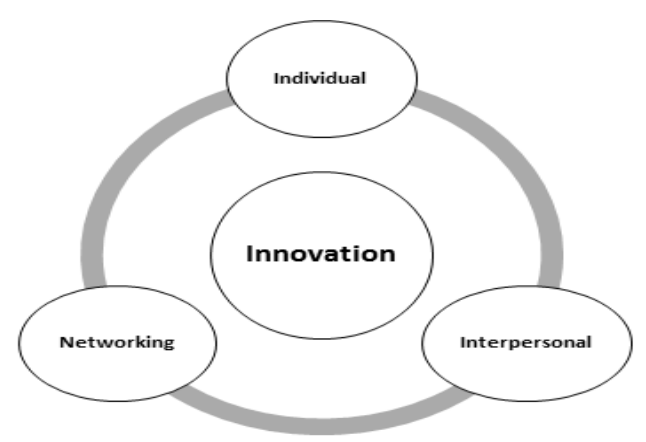

Figure 1. Dimensions of innovation competence (Marin-Garcia et al., 2013)

$f b$

$f b$

$f b$

$n$

$\mathbf{W}$

3. Research Questions

$\bullet$

$\bullet$

$\bullet$ 
4. Methodology 
5. Next steps for ongoing research

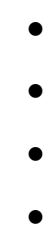


Acknowledgements

References 


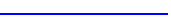
- 